\title{
An Iceberg Model for Improving Mathematical Understanding and Mindset or Disposition: An Individualized Summer Intervention Program
}

\author{
ARLA WESTENSKOW AND PATRICIA S. MOYER-PACKENHAM, UTAH STATE UNIVERSITY; AND BARBARA CHILD, \\ LOGAN CITY, UTAH, SCHOOL DISTRICT
}

\section{ABSTRACT}

This study describes 3 years of mathematics intervention research examining the effectiveness of a summer individualized tutoring program for rising fourth-, fifth-, and sixth-grade students with low mathematics achievement. Based on an iceberg model of learning, an instructional framework was developed that identified and targeted students' specific mathematical needs, developed number sense flexibility, and encouraged positive mindset or disposition. Students participated in eight one-on-one tutoring intervention sessions. Pre- and posttest results indicated that students made moderate to large effect size gains in each targeted area of instruction. Additionally, the intervention proved to produce positive results across three different contexts for delivering tutoring instruction.

Recently, there has been a shift toward earlier intervention for students who struggle with mathematical learning (Fuchs, 2005). The goal is to remediate difficulties for students who do not respond to regular classroom instruction before those difficulties compound and students require more intensive special education support (Vaughn, 2011). Toward that end, the intervention program reported in this article was informed by the tier system of Response to Intervention (RTI) (Gersten \& Newman-Gonchar, 2011). In Tier I, or classroom instruction, the purpose is to introduce and develop new areas of understandings. In Tier III, or special education instruction, the purpose is to provide intense continuous instruction to help students overcome difficulties connected to a moderate to severe learning disability. Tier II students are those who do not adequately respond to classroom instruction, but who do not receive special education services (Vaughn, 2011). The purpose of Tier II intervention is to identify gaps and build missing knowledge to improve students' understanding and resolve misconceptions. Currently, there is limited research, and few materials and programs are available to address the unique needs of students who require Tier II intervention (Gersten \& Newman-Gonchar, 2011). The purpose of this study was to describe and evaluate the development and implementation of a project that began as a summer program in a clinical setting and progressed to a teacher-directed summer program in a local school setting.

\section{LITERATURE REVIEW}

Development of the Targeted Mathematics Intervention (TMI) program was based on a review of the literature on mathematics learning difficulties. The review identified three main factors that typically limit Tier II students' ability to develop mathematical understanding: incorrect or insufficient content understanding, lack of number sense flexibility, and a negative mindset or disposition.

\section{Incorrect or Insufficient Content Understanding}

Mathematics is a discipline in which new concepts are built upon previously learned concepts; thus incorrect or insufficient knowledge of basic concepts limits future mathematical growth (Fuchs, 2005). The main goal of Tier II interventions is to remediate areas of insufficient understanding and misconceptions that limit student growth. Learning gaps may be caused by missed opportunities, inadequate teaching, absenteeism, second language learning, difficulties attending to instruction, or cognitive or physical disabilities (e.g., memory, visual perception, senses) (Dowker, 2005; Geary, 2010). Although the large range of causes and the complexity of student understanding make the identification and remediation process difficult and time-consuming, teachers must identify students' mathematical strengths and weaknesses and develop intervention plans tailored to their needs (Dettori \& Ott, 2006).

\section{Lack of Number Sense Flexibility}

In a summary of the number sense literature, Markovits and Sowder (1994) defined number sense as a "disposition to make sense of numerical situations" (p. 5). When students demonstrate number sense they are connecting ideas across characteristics of number (e.g., magnitude, symbols, and representations) and the use of numbers (e.g., estimating, comparing, and operations). One important element of strong number sense is a student's ability to use numbers and operations in flexible ways. Research indicates that students who struggle with mathematics often have limited mental mathematics skills and rely heavily on the use of standard algorithms (Markovits \& Sowder, 1994; Varol \& Farran, 2007). Some students focus solely on the algorithm steps and do not consider sense-making strategies, such as number magnitude or sense-making methods of calculation (Shumway, 2011). It is not uncommon for fifth- and sixth-grade Tier II students to use 
the standard algorithm to calculate simple sums such as $199+4$ or $161+6$ (Westenskow, Moyer-Packenham, \& Child, 2014). While there is controversy in the literature about how number sense flexibility should be encouraged, much of the work suggests that number sense flexibility is best developed through extensive opportunities to manipulate numbers as students discover more efficient strategies (e.g., Carpenter, Franke, Jacobs, Fennema, \& Empson, 1998; National Research Council, 2001). Other studies have demonstrated that students can benefit from explicit instructional approaches (e.g., Blote, Klein, \& Beishuizen, 2000; Yang, 2003).

\section{Negative Mindset or Disposition}

Mathematical mindset or disposition refers to students' attitudes and beliefs about mathematics and their motivation and confidence for performing mathematical tasks (Van De Walle, 2004). Research suggests that, in the United States, elementary students typically enter school with positive attitudes toward mathematics, but many fail to maintain these attitudes as they progress through the grades (Cotton, 2004). Nardi and Steward (2002) observed that when students found lessons to be 'too difficult,' they gave up and expressed feelings of anger, dissatisfaction, and doubt about their own abilities. Repeated failure causes some students to develop mathematics anxiety and habits of avoidance (Clayton, Burton, Wilson, \& Neil, 1988). These feelings inhibit mathematics development, and students become locked into the cycle of failure (Figure 1 , first circle). In contrast, students with a positive mindset or disposition see mathematics as useful, worthwhile, and attainable and are motivated to engage in mathematics (Gadanidis, 2004). As students experience pleasure in learning new concepts they become involved in a cycle of engagement, confidence, pleasure, and motivation (Figure 1, second circle).

\section{DEVELOPMENT OF THE TARGETED MATHEMATICS INTERVENTION (TMI) SUMMER PROGRAM}

We developed the Targeted Mathematics Intervention summer program to address the gaps in mathematical content understanding, lack of number sense flexibility, and a negative mindset or disposition.

\section{Iceberg Intervention Model to Identify Specific Gaps in Content Understanding}

The need to identify and address Tier II students' misconceptions and lack of understandings has been identified by a number of researchers (e.g., Dettori \& Ott, 2006; Dowker, 2005; Ma, 1999). To address this need, we adapted the iceberg metaphor of learning trajectories used by the Freudenthal Institute (see Webb, Boswinkel, \& Dekker, 2008) to develop three Iceberg Intervention Models (place value, multiplication, and division). Each model was based on the literature and revised based on ongoing research. For example, when developing the place value iceberg model we first surveyed the literature to identify the foundational topics that explain the elements for understanding place value and to determine areas in which students typically struggled. We then synthesized the findings into a place value

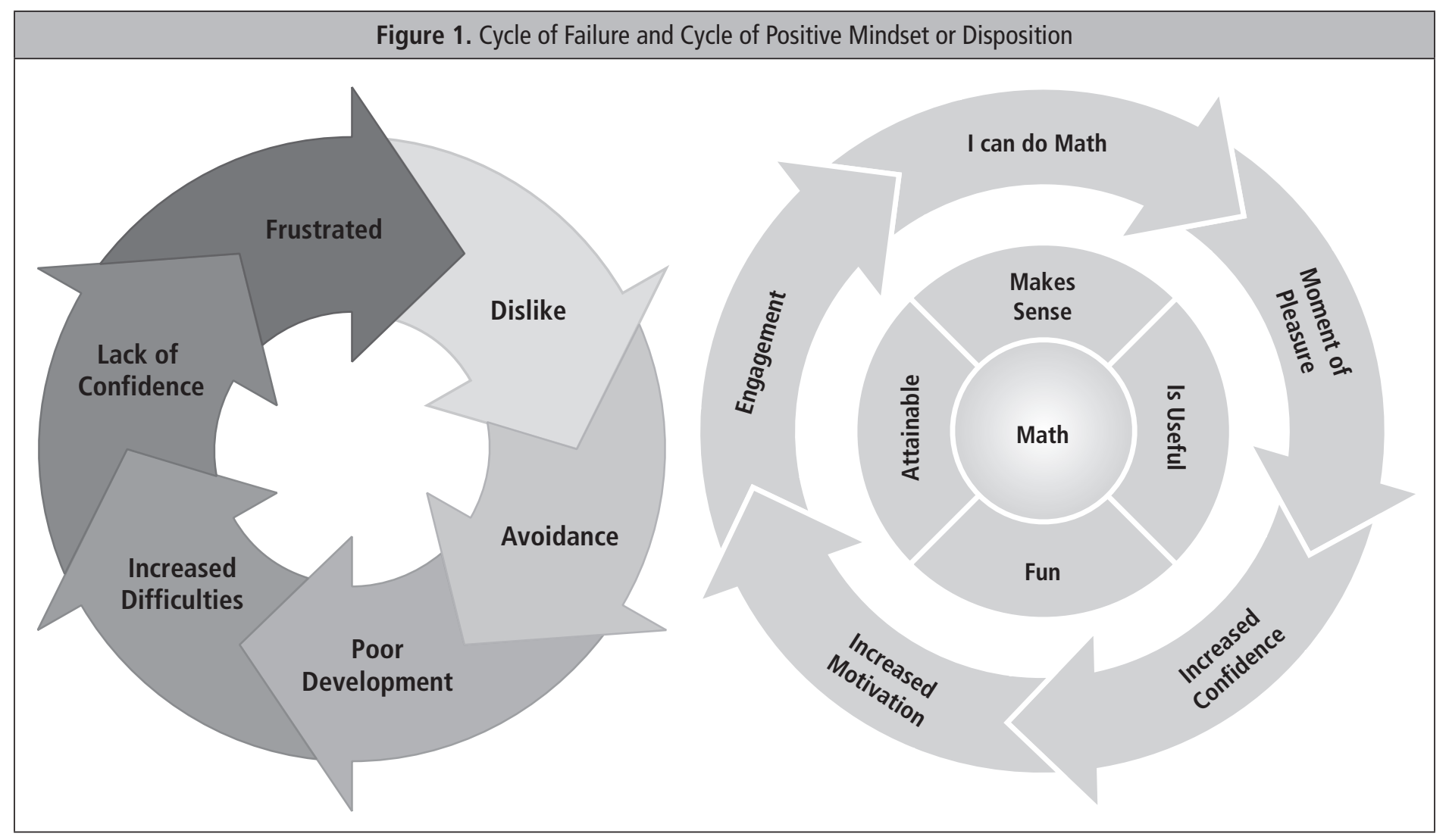


iceberg model (see Figure 2). As suggested by the work of Ma (1999), there are foundational mathematical concepts that are necessary to the understanding of higher level concepts. For place value, we identified from the literature as foundational skills the components of estimating number magnitude, counting, and coordinating groups of ten (Dowker, 2001; Ellemor-Collins \& Wright, 2007; Shumway, 2011). In the iceberg these skills are placed at the bottom, under the waterline. Although these skills are not typically assessed in upper elementary grades, they are necessary for the foundational development of the Level 2 understanding of decomposing/composing, regrouping, position value, and understanding relationships between place value positions. These four components involve coordinating units within and between place value positions (Fuson, 1990; Varelas \& Becker, 1997). Understanding Level II components enables students to apply place value understandings when working with the Level I concepts of comparing numbers, performing mental math, and reading and writing numbers (Bills, 2003). Level I skills are placed at the top or tip of the iceberg above the water line. These are the place value understandings that are more frequently taught and assessed in the upper elementary and middle school grades. Mastery of Level I understandings and skills reflects the student's ability to flexibly apply place value understandings in problem-solving situations. However, these Level I understandings rest on the foundation of the Level 2 and Level 3 understandings and skills.

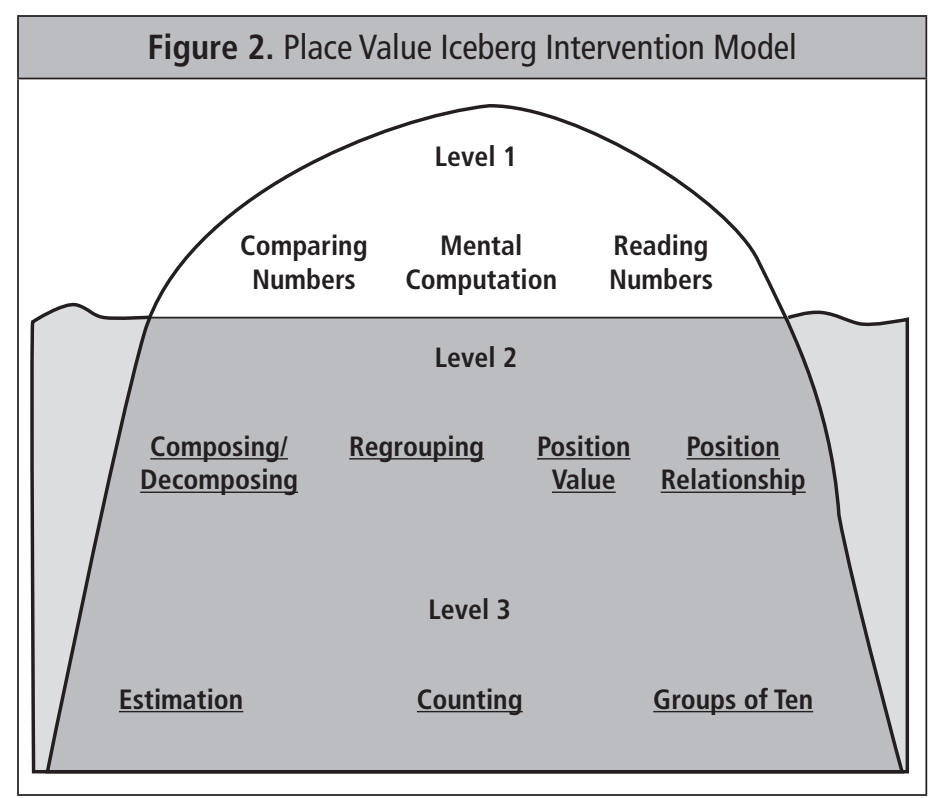

After the initial development of an iceberg model, a team of researchers and school-based educators evaluated the models for theoretical validity and potential usefulness in determining a student's strengths and needs. Using the Iceberg Intervention Models as frameworks, we developed diagnostic assessments for each iceberg model component. For example, to create assessment items for the Comparison Component of Level I of the Place Value Assessment, we developed questions for three comparing concepts: (1) magnitude (e.g., Which of the numbers shown $[12,323 ; 11,981$; or 9,999$]$ is the greatest? Which is the least?); (2) order (e.g., This number line shows the numbers 470 and 490. What number do you think the $\mathrm{x}$ represents?); and (3) density (e.g., Tell me a number that comes between 410,000 and 411,000$)$. For each question, we developed rubrics to identify the level of understanding exhibited by student responses. We then administered the test to students with mathematical learning difficulties and used the results to develop individual intervention plans targeting the specific needs of each student. In an ongoing process data results were analyzed, and models and assessments were and continue to be refined to improve their usefulness as tools for researchers and teachers. Following this process, iceberg models were developed for place value, operations, and fractions, as well as third-, fourth-, and fifth-gradelevel diagnostic assessments currently used in clinical and school settings. For a detailed explanation of the development of the fraction iceberg model see Westenskow (2012) and Westenskow and Moyer-Packenham (2016).

\section{Number Sense Strategy Instruction to Increase Number Sense Flexibility}

To address the second factor, increasing number sense flexibility, we adopted a two-step explicit approach. First, as suggested by Threlfall (2002), we presented a problem and built on the connections between what students noticed about the problem and their number sense understanding (e.g., in the problem $99+14$, students noticed that 99 was only one from 100, and therefore knew that they could subtract one from 14 to get the sum of 113). Second, we guided students in verbalizing their newly developed strategies and provided opportunities to practice the strategies in different contexts. Because of the advantages identified in the literature, we placed a strong emphasis on the use of mental mathematics strategies (Varol \& Farran, 2007).

\section{Positive Mindset or Disposition}

To encourage positive mindset or disposition, we used two practices in all tutoring sessions: (1) the zone of proximal development approach (ZPD) (Vygotsky, 1978) in one-to-one tutoring and (2) playing mathematical games. Learning new concepts and resolving misconceptions entails a critical time of mental conflict as students integrate new and old understandings and challenge previously held misconceptions (Vosniadou \& Brewer, 1987). In one-to-one tutoring the teacher can work within the ZPD, guiding and empowering students while monitoring for appropriate levels of challenge and mental conflict. Research suggests that playing games increases motivation and confidence (Ke \& Grabowski, 2007; Young-Loveridge, 2004). Each intervention lesson included two or three mathematical games designed to give students practice in the newly learned concepts.

Addressing the three main factors that limit Tier II students' ability to develop mathematical understanding was an important priority for our intervention. 


\section{METHODS}

To examine the effectiveness of the TMI program we used a concurrent triangulation mixed method design (Creswell \& Clark, 2007). Quantitative analysis was used to compare pre- to posttests of concept understanding and number sense flexibility. Qualitative analysis was used to examine changes in students' mindset or disposition. The overarching research question guiding this study was: How does participation in a TMI summer intervention program affect students' content understanding, number sense flexibility, and mindset or disposition? (a) How do students' pre- to posttest scores in content understanding differ? (b) How do students' pre- to posttest scores in number sense flexibility differ? (c) What changes in the students' mindset or disposition were observed?

\section{Participants and Setting}

During development, the TMI Summer Intervention Program transitioned from a university clinical intervention to researcher-led intervention in the schools to teacher-led intervention in students' local schools. The participants came from two school districts in the area of a rural city in the western United States. There were 16 elementary schools in the rural district and 6 elementary schools in the city school district.

Year 1. In the initial year fourth-grade teachers in two school districts were asked to identify Tier II students who did not qualify for special education services, but who consistently struggled with mathematics concepts during regular instruction. The teachers gave these students recruitment letters advertising free mathematics tutoring at the local university. Of the 41 participating students ( $43 \%$ female and $57 \%$ male) $56 \%$ qualified for the school's free/ reduced lunch programs. Seven students had received special education services for mathematics in the past year. Students attended an average of 7.6 of 8 one-to-one tutoring sessions. Thirty-one students took the number sense pre- and posttests; 30 the operation pre- and posttests; and 7 also took the fraction pre- and posttests. Parents were asked to remain on site during the tutoring sessions, and most parents observed the tutoring from an audio observer booth equipped with two-way mirrors. The tutor/researcher had 30 years of classroom teaching experience.

Year 2. The local school district provided funding to tutor 29 ( $52 \%$ female and $48 \%$ male) rising sixth-grade students. The district had 6 Title 1 elementary schools. Each school identified and invited Tier II students with low mathematics achievement to participate in 10 sessions of individual tutoring held at the students' local schools. Of the 29 students, 27 took the number sense pre- and posttests, and 25 took the place value or fraction pre- and posttests. Students attended an average of 7.9 of the 10 one-to-one tutoring sessions, which were conducted by a university researcher and the district mathematics specialist. Each tutor had over 25 years of teaching and intervention experience.

Year 3. In the final year, the third-grade teachers in the district identified and recruited 37 (59\% female and 41\% male) rising fourth-grade students with low mathematics achievement. Thirty-one students took the number sense pre- and posttests and 34 the place value preand posttests. During the two weeks of tutoring, students attended an average of 7.9 of the 10 sessions. Tutoring was conducted by 13 district teachers who had an average of 9.9 years teaching experience. Teachers volunteered to participate and attended two days of training prior to providing tutoring for the students.

\section{Instruction}

The same basic instructional plan and session format was used during all 3 years. During the initial tutoring session, instructors administered a Number Sense Inventory and a Diagnostic Iceberg Intervention assessment. The focus of the pretests correlated with the main instructional content focus of the grade level of the previous year: Grade 3, place value; Grade 4, operations; and Grade 5, fractions. Test results were used to develop individualized intervention plans for each student. Tutoring sessions lasted 45-55 minutes and were divided into three parts. In the first 5-10 minutes, students completed daily assessments. The daily assessments were used to monitor progress and inform the selection of lessons and activities. Next, there were 10-20 minutes of number sense flexibility instruction. In the final 30-40 minutes instruction focused on place value, operations, or fraction content understanding as identified in the pretests. During the third year, instructors downloaded lesson plans and activities from a website that was developed by the researchers in the first two years.

Learning activities emphasized developing procedural and conceptual understanding and were typically taught using a guided problem-solving approach. Students progressed from solving problems using manipulatives to symbolic-only representations. An example of a guided lesson was teaching the concept of multiplying multiples of ten. Instructors asked students to use base ten rods to model and solve $10 \times 10,20 \times 10,200 \times 10$, etc. Students were guided to infer a rule for multiplying by ten. A second example was the use of the National Library of Virtual Manipulatives base ten blocks to solve regrouping subtraction problems. In the app, students are guided through the regrouping process. Following the activity, tutors asked students to explain connections between the manipulative regrouping and the standard algorithm. The regrouping process of bringing one flat or block rod from the position to the left and watching it break into ten of the manipulatives of the position to the right helped students to understand the standard algorithm process of regrouping. Following each lesson, students practiced concepts by playing mathematical games for the concept being taught.

\section{Instruments and Data Analysis}

We used four instruments: Number Sense Inventory, Number Sense Daily Assessments, Diagnostic Iceberg Assessments, and Parent/Teacher Surveys.

Number sense inventories. We administered the Mathematics Reasoning Inventory (MRI) for whole numbers as a pre- and posttest to all Year 1 and Year 2 students and an MRI for fractions to 21 students 
in Year 2 (https://mathreasoninginventory.com/). MRI assessments have two sections. The first section asks 10 number sense questions, and the second section poses 4 operation problems. In Year 3, we developed and implemented a similar inventory for third-grade concepts. To measure growth on the inventories, we used rubrics to evaluate correctness and efficiency of students' strategies and responses. A panel of five experts in mathematics education evaluated the rubrics with a rate of $100 \%$ agreement. We analyzed the pre- and posttest results using paired samples $t$-tests and Cohen $d$ effect size scores and created graphs comparing pre- and posttest results for each question.

Daily number sense/fraction flexibility monitoring assessments. These assessments included five to six questions. The questions and scoring rubrics were similar in structure to the MRI assessments. Results were averaged, and line plots were developed.

Iceberg diagnostic assessments. We developed Place Value, Multiplication, and Division Iceberg Model Diagnostic assessments. We scored responses and developed iceberg models showing the percent correct for each student. In Years 2 and 3, we administered the Place Value Iceberg Model Diagnostic assessment as a posttest during the final tutoring session. We compared pre- and posttest scores using paired samples $t$-tests and calculated Cohen $d$ effects scores.

Parent/teacher surveys. At the end of Year 1, 24 parents completed an anonymous 18-question open-response survey designed to gather the following information: (1) parents' background and academic experiences in mathematics, (2) methods and practices observed by the parents, (3) parent and perceived child attitudes and beliefs about mathematics, and (4) insights about the child's mathematical understanding. In Year 3, teachers completed an anonymous online questionnaire about their tutoring experience. Eleven of 13 teachers participated. We used thematic analysis (Patton, 1990) and open and axial coding (Strauss \& Corbin, 1990) to analyze parent and teacher responses for common themes relating to students' mindset or disposition. For a detailed analysis of parent responses, see Westenskow, Boyer-Thurgood, and Moyer-Packenham (2015).

\section{RESULTS}

For each year of the study, results are reported for the three areas of focus: content understanding, number sense flexibility, and mindset or disposition.

\section{Content Understanding}

In Year 1, the content focus of the interventions was on developing mastery of whole number operations. However, analysis of students' errors and difficulties during the tutoring sessions indicated that many of the difficulties stemmed from a lack of place value understanding. Therefore, following the Year 1 summer program, we developed and piloted an Iceberg Place Value Model and diagnostic assessment to use in subsequent years. When students' pretest diagnostics indicated mastery of place value and operations, the focus of their intervention shifted to fractions. Table 1 summarizes the assessment results for each content area. The Cohen $d$ effect size analysis yielded moderate to large effect sizes for all 3 years. The following section provides a detailed account of the content assessments by program years.

\begin{tabular}{|c|c|c|c|}
\hline \multicolumn{4}{|c|}{$\begin{array}{l}\text { Table 1. Summary of Pre- to Posttest Content Cohen } d \\
\text { Effect Size Comparisons }\end{array}$} \\
\hline Year & $\begin{array}{l}\text { Year } 1 \\
\text { Grade } 4\end{array}$ & $\begin{array}{l}\text { Year } 2 \\
\text { Grade } 5\end{array}$ & $\begin{array}{l}\text { Year } 3 \\
\text { Grade } 3\end{array}$ \\
\hline $\begin{array}{l}\text { Primary Focus } \\
\text { Number }\end{array}$ & $\begin{array}{l}\text { Operations } \\
N=30\end{array}$ & $\begin{array}{l}\text { Place Value } \\
N=8\end{array}$ & $\begin{array}{l}\text { Place Value } \\
N=34\end{array}$ \\
\hline $\begin{array}{l}\text { Results } \\
\text { Instrument } \\
\text { Effect Size Gain }\end{array}$ & $\begin{array}{l}\text { MRI - Operations } \\
1.23\end{array}$ & $\begin{array}{l}\text { PV Iceberg } \\
0.74\end{array}$ & $\begin{array}{l}\text { PV Iceberg } \\
0.63\end{array}$ \\
\hline Secondary Focus & $\begin{array}{l}\text { Fractions-Equivalent } \\
N=7\end{array}$ & $\begin{array}{l}\text { Fraction Operations } \\
N=21\end{array}$ & $\begin{array}{l}\text { Fractions-Naming } \\
N=3\end{array}$ \\
\hline $\begin{array}{l}\text { Results } \\
\text { Instrument } \\
\text { Effect Size Gain }\end{array}$ & $\begin{array}{l}\text { Fraction Monitors } \\
1.09\end{array}$ & $\begin{array}{l}\text { MRI - Fractions } \\
0.75\end{array}$ & $\begin{array}{l}\text { No data were } \\
\text { collected }\end{array}$ \\
\hline
\end{tabular}

Operation mastery: Year 1. The operation subtest of the Number MRI assessment was comprised of four symbolic operation problems. Of the 25 students who completed pre- and posttests, on the pretest, $60 \%$ correctly solved the subtraction problem; $28 \%$, the double-digit multiplication problem; 4\%, the single digit division problem; and 12\%, the double-digit division problem. All students used standard algorithms except one who unsuccessfully used a lattice strategy for multiplication and an array strategy for division.

To identify the source of students' difficulties, we administered Multiplication Iceberg Diagnostic Assessments to 21 students and Division Iceberg Assessments to 8 students. We found three student weaknesses in multiplication and division: multiplication and division by powers of 10 , estimation skills, and solving word problems. Using the iceberg diagnostic results, we developed individual lessons addressing students' needs. For most students, the initial lessons of each operation focused on developing partial product strategies and linking symbolic procedures to the manipulation of objects (money, base ten blocks, and virtual manipulatives) in problem-solving contexts. Subsequent lessons focused on developing procedural fluency and strengthening estimation skills. Pre- to posttests on the four operation questions showed significant averaged gains $(\mathrm{F}(2,29)=5.9, p=0.00)$ and a large Cohen $d$ effect size of 1.23 .

Place value and fraction understanding: Year 2. In the second year, the content focus was place value and fraction understanding. The pretest number sense inventory suggested that 8 of the 29 rising sixth graders struggled with place value concepts. We administered Iceberg Place Value Diagnostic assessments and developed individual plans of instruction. Pre- to posttest results showed a moderate to large Cohen d effect size score for all concepts except regrouping (see Table 2). However, because of the small sample size and the large standard deviations, the results give only a general picture and guide for future research. 
Table 2. Year 2 Place Value Pre- to Post-Iceberg Diagnostic Comparisons

\begin{tabular}{|l|c|c|c|c|c|c|c|c|c|}
\hline Place Value Content & \multicolumn{2}{|c|}{ Pretest } & \multicolumn{3}{|c|}{ Posttest } & \multicolumn{4}{|c|}{. } \\
\hline & Mean & SD & Mean & SD & Gain & $\boldsymbol{d f}$ & $\boldsymbol{t}$ & $\boldsymbol{p}$ & Effect Size \\
\hline PV Mental Math & 54.21 & 17.28 & 72.73 & 37.75 & 18.5 & 7 & 1.59 & .16 & 0.69 \\
\hline Comparing Numbers & 51.25 & 36.43 & 82.50 & 13.89 & 31.2 & 7 & 2.81 & .02 & 1.13 \\
\hline Reading/Writing Numbers & 58.75 & 19.59 & 71.25 & 23.87 & 12.5 & 7 & 1.52 & .17 & 0.57 \\
\hline Regrouping & 60.53 & 25.96 & 65.19 & 19.67 & 4.66 & 6 & 1.27 & .25 & 0.20 \\
\hline PV Representations & 66.77 & 27.35 & 80.05 & 15.244 & 13.28 & 5 & 1.35 & .24 & 0.60 \\
\hline Position Values & 69.57 & 29.22 & 89.43 & 8.36 & 19.86 & 6 & 2.06 & .08 & 0.92 \\
\hline Position Relationships & 51.29 & 19.02 & 70.43 & 16.24 & 19.14 & 6 & 4.90 & .00 & 1.08 \\
\hline
\end{tabular}

\begin{tabular}{|l|c|c|c|c|c|c|c|c|}
\hline \multicolumn{9}{|c|}{ Table 3. Year 3 Place Value (Grade 3) Pre- to Posttest Iceberg Diagnostic Comparisons } \\
\hline & \multicolumn{2}{|c|}{ Pretest } & \multicolumn{2}{c|}{ Posttest } & \multicolumn{4}{c|}{ Paired Samples Test } \\
\cline { 2 - 11 } & Mean & SD & Mean & SD & $\boldsymbol{t}$ & $\boldsymbol{d f}$ & $\boldsymbol{p}$ & Effect Size \\
\hline Decomposing & 13.79 & 3.01 & 15.71 & 2.50 & 3.95 & 33 & 0.00 & 0.70 \\
\hline Regrouping & 14.56 & 3.77 & 17.47 & 2.72 & 5.70 & 33 & 0.00 & 0.88 \\
\hline Positions & 16.03 & 3.55 & 17.82 & 1.91 & 2.65 & 33 & 0.01 & 0.63 \\
\hline Relationships & 12.58 & 3.31 & 13.68 & 3.03 & 2.54 & 33 & 0.02 & 0.29 \\
\hline
\end{tabular}

$N=34$

The intervention focus for the remaining 21 students in Year 2 was fractions. The pretest Fraction MRI indicated that most of the students had mastered basic fraction operation algorithms of addition, subtraction, multiplication, and division, but struggled with applying fraction concepts in problem-solving contexts. From the Fraction MRI pretest analysis, we identified five areas of focus: comparing magnitude, estimating with addition and subtraction, finding missing addends, doubling fractions, and halving fractions. We developed lessons and activities promoting fraction sense in each of the five areas then collected pre- and posttest Fraction MRI data on 17 of the 21 students. A paired samples $t$-test analysis resulted in a significant averaged gain $(\mathrm{F}(2,16)=3.74, p=0.00)$ and a moderate Cohen d effect size of 0.75.

Place value understanding: Year 3. In the final year, with the focus of the intervention on place value understanding, we administered Iceberg Intervention Diagnostic assessments to all students and developed individual plans of instruction. Teachers focused on Level 2 of the Iceberg Intervention Model. Analysis of pre- to posttests resulted in a moderate to large Cohen $d$ effect size score for all concepts except place value relationships (see Table 3).

\section{Number Sense Flexibility}

The procedures for the number sense assessments and data collection were similar for all 3 years. From pretest Number Sense Inventories, we identified five concepts where the majority of students struggled. The topics selected for third-grade level were doubling, halving, number line placement, rounding, and adding powers of 10. The topics for fourth- and fifth-grade levels were mental math addition, multiplying/dividing by powers of ten, estimation, and adding to numbers that are close to a century transition. During each session students participated in a 10-minute number sense lesson and completed a daily monitoring quiz. The averaged results from the monitor quizzes are shown in Figure 3. In all 3 years there was a steady rate of growth across the duration of the sessions suggesting that students retained the concepts taught from session to session. Pre- to posttest paired samples $t$-test comparisons of the number sense inventories indicated that growth was significant for all 3 years, with large effect size scores of 1.27 in Year 1, 1.87 in Year 2, and 1.68 in Year 3.

Figure 3. Number Sense Learning Trajectories for Year 1, Year 2, and Year 3

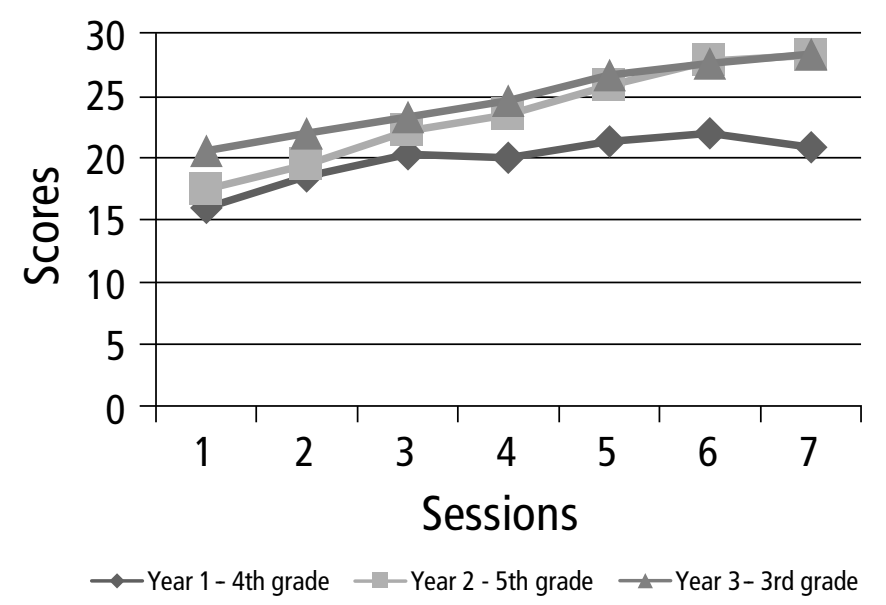

$N$. Year $1=31$, Year $2=29$, and Year $3=34$

We completed pre- to posttest comparisons for each question on the Number Sense Inventory to determine which concepts showed 

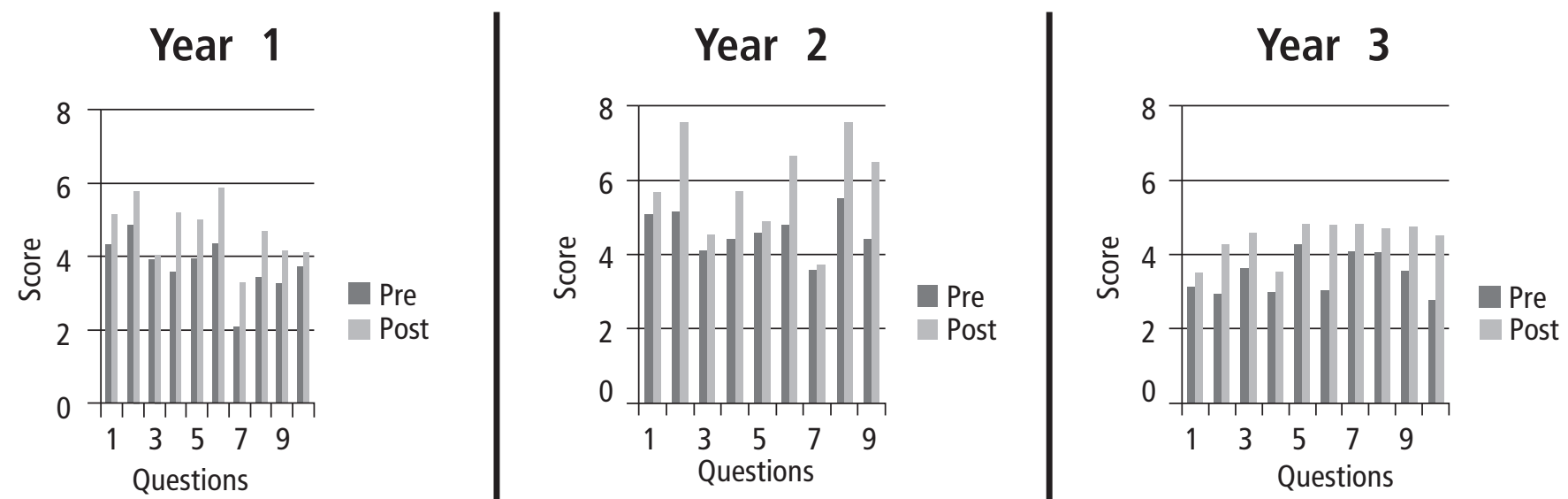

$N=31 \quad N=29 \quad N=31$

gains (see Figure 4). In all years, posttest scores were higher than pretest scores for all 10 questions.

\section{Mindset or Disposition}

The third focus of the TMI intervention was the development of positive mindset or disposition toward mathematics. To document these shifts, we collected information on indicators suggesting a positive mindset or disposition (see Table 4).

\begin{tabular}{|l|c|c|c|}
\hline \multicolumn{4}{|c|}{ Table 4. Indicators of Positive Mindset or Disposition } \\
\hline Indicators & $\begin{array}{c}\text { Year 1 } \\
\text { Grade 4 }\end{array}$ & $\begin{array}{c}\text { Year 2 } \\
\text { Grade 5 }\end{array}$ & $\begin{array}{c}\text { Year 3 } \\
\text { Grade 3 }\end{array}$ \\
\hline $\begin{array}{l}\text { Averaged percent of sessions } \\
\text { attended }\end{array}$ & $76.0 \%$ & $87.7 \%$ & $79.0 \%$ \\
\hline $\begin{array}{l}\text { Averaged increase of percent } \\
\text { of problems attempted from } \\
\text { pre- to posttest }\end{array}$ & 87.5 to 95.4 & 96.2 to 98.9 & 83.8 to 97.7 \\
\hline $\begin{array}{l}\text { Averaged increase of percent } \\
\text { of questions students } \\
\text { answered using mental math }\end{array}$ & 22.6 to 39.9 & 32.4 to 69.0 & 51.4 to 80.5 \\
\hline
\end{tabular}

Attendance for summer school programs is voluntary and often affected by conflicting family and sports activities. During Year 1 of this program, parents and students attended 76\% of the sessions, suggesting that they valued the tutoring opportunities enough to overcome conflicts. As the study was implemented in the schools, students attended the sessions on their own, and attendance remained high at $88 \%$ in Year 2 and 79\% in Year 3. Tutors reported that most students became very involved in the activities. One tutor reported: [I liked] "to watch kids change from hating math to loving it. They got so excited when they came in every day, and some of them wouldn't leave!" In the Year 1 parent surveys, $38 \%$ reported that the tutoring showed that mathematics could be enjoyable for their children.
A second indicator of change in mindset or disposition was the increase of students who attempted to answer the pre/post number sense flexibility inventory questions. Responses were counted as non-attempts when students responded: "I don't know" or made a random guess. The percent of students attempting the pre- and posttest inventory questions increased in all 3 years. The game-like structure of the tutoring activities made mathematics more enjoyable, built confidence, and encouraged students to persevere. One Year 3 teacher wrote, "Students will do hard math and keep trying if they can have a chance to flip an ant into the pants (a game activity).”

A third indicator of mindset or disposition change was the increase in students' use of mental mathematics in the pre/post number sense flexibility inventories, suggesting an increase in confidence in their ability to manipulate numbers. The percent of students using mental mathematics strategies for each inventory question increased in all 3 years.

During Year 1, in parents' responses to the open-ended question: Have you observed any change in your child's attitudes or feeling toward mathematics during the tutoring sessions? they stated that their children were more positive and confident when doing mathematics, more willing to work out problems, and enjoyed mathematics more than they had before the tutoring sessions. In a follow-up interview, one parent described the change she observed in her daughter:

In fifth grade she seems to be approaching her math homework a lot better. She has not burst into tears telling me how difficult it is even once this year. I think that a lot of that is because of the help over the summer.

\section{DISCUSSION}

The results of the Iceberg Diagnostic assessments in this study indicated that new mathematical learning for Tier II students may have been limited because they had not mastered concepts they should 
have mastered in earlier instruction. For example, pretest analyses in all 3 years indicated that many students struggled with the concept that each place value position is 10 times the number to its right and $1 / 10$ of the number to its left. This limited students' ability to comprehend procedures in multiplication and division and estimate quotients in division. These findings suggest that an important part of Tier II intervention is a focus on the identification and intervention of deeper sub-concept weaknesses that limit students' understanding and flexibility in problem solving.

Even when the need for intervention of sub-concepts is apparent, it is difficult for teachers to find the time to plan and conduct the interventions. A summer intervention program can support students and has the advantage of helping them make mathematical progress during a time when most students regress. This study suggests that, even in a summer program of 8 to 10 sessions, students can make significant gains in mathematical content knowledge. The gains were attainable across three different contexts: a clinical setting with tutoring conducted by a researcher, a school setting with tutoring conducted by researchers, and a local school setting with tutoring conducted by the teachers. This study revealed three important aspects that contributed to student gains: (1) targeted content focus through diagnostic testing and one-to-one tutoring, (2) instruction promoting flexible number sense, and (3) an environment promoting positive mindset or disposition toward mathematics.

\section{Targeted Content Focus}

The Iceberg Models of assessment helped tutors identify areas of difficulties for each student. Once the areas were identified daily monitoring assessments enabled the tutors to determine students' development and retention of concepts and to tailor instruction to the students' individual needs. The consistent positive gains across all three settings indicated that teachers can successfully use the Iceberg Intervention Model assessments to identify Tier II students' mathematical sub-concept needs in order to provide targeted remediation.

This study also raises the important question of whether it is more efficient to use time and money to provide group instruction (as proposed by most intervention models) or one-to-one instruction (as in this study). We propose that the group model is effective and efficient when re-teaching concepts presented recently in the students' classroom. However, one-to-one tutoring may be a more effective and efficient method for remediating concepts and skills at a deeper level of understanding on the iceberg model. An important advantage of one-to-one instruction is the flexibility it affords in working within each student's ZPD. Although students may have similar levels of content understanding, they often have very different instructional needs (Dettori \& Ott, 2006).

\section{Flexible Number Sense Instruction}

The question has been raised as to whether students must learn number sense flexibility through discovery or an explicit approach to number sense flexibility strategies (Gersten, 1999). In this study we taught five to six number sense flexibility strategies to students each year with successful results. However, further research is needed to determine if the students were able to transfer these strategies to other settings. Two findings in this study suggest that this was the case. First, for all 3 years, number sense pre- and posttest results suggested that students' use of efficient or flexible strategies increased not only on questions requiring the number sense skills that were explicitly taught, but also on questions requiring skills that were not explicitly taught. Second, test results indicated that students' use of mental math strategies increased. Both findings suggest that explicit instruction of number sense strategies may be useful in helping students increase their use of number sense thinking during problem-solving activities.

\section{Emphasis on Student Mindset or Disposition}

Although difficult to measure and study, most agree that a positive mindset or disposition towards mathematics is vital to the success of students who struggle with mathematics (National Research Council, 2001). Learning new concepts requires perseverance and confidence. The game format used for the tutoring activities promoted engagement and, as noted in the parents' observations, promoted students' confidence in their mathematical abilities. For students who continually struggle in mathematics classrooms and typically lose mathematics games, winning can become a positive confidence builder and help break the negative mindset or disposition cycle. A second aspect of the program that promoted a positive mindset or disposition was the use of short mini lessons or lesson strands. This structure required only short periods of focused attention to understand small amounts of information. New understandings were practiced and deepened in game-like activities. This combination of short focused learning and practice games allowed students to experience success and gain confidence in their ability to learn. Students' repeated successes helped them to move from a negative to a positive cycle.

Another critical factor was the way the three strands of focus of the TMI program are intertwined. Content understanding, number sense flexibility, and students' mindset or disposition affect and are affected by the other two strands. The structure of the program allowed tutors to address and intertwine the three areas of focus in an environment free from many of the social distractions hindering classroom intervention. Although further research is needed on the long-term effects of the summer program, short-term results suggest that a targeted mathematics intervention summer tutoring program can be used in multiple settings and can be a beneficial supplement to school classroom interventions.

\section{References}

Bills, C. (2003). Errors and misconceptions in KS3 'number.' Proceedings of the British Society for Research into Learning Mathematics, Londres, 23(3), 7-12.

Blote, A. W., Klein, A. S., \& Beishuizen, M. (2000). Mental computation and conceptual understanding. Learning and Instruction, 10, 221-247.

Carpenter, T. P., Franke, M. I., Jacobs, V. R., Fennema, E., \& Empson, S. B. (1998). A longitudinal study of invention and understanding in 
children's multidigit addition and subtraction. Journal for Research in Mathematics Education, 29(1), 3-20.

Clayton, G. A., Burton, K., Wilson, B., \& Neil, M. (1988). Effective mathematics teaching: Remediation strategies: Grades K-5. Triangle Park, NC: Southeastern Educational Improvement Research Lab.

Cotton, T. (2004). Inclusion through mathematics education. Mathematics Teaching, 187(June), 35-40.

Creswell, J. W., \& Clark, V. L. P. (2007). Designing and conducting mixed methods research. Thousand Oaks, CA: Sage.

Dettori, G., \& Ott, M. (2006). Looking beyond the performance of grave underachievers in mathematics. Intervention in School and Clinic, 41(4), 201-208.

Dowker, A. (2001). Numeracy recovery: A pilot scheme for early intervention with young children with numeracy difficulties. Support for Learning, 16(1), 6-10.

Dowker, A. (2005). Individual differences in arithmetic: Implications for psychology, neuroscience and education. New York, NY: Psychology Press.

Ellemor-Collins, D., \& Wright, R. (2007). Assessing pupil knowledge of the sequential structure of numbers. Educational and Child Psychology 24(2), 54-63.

Fuchs, L. S. (2005). Prevention research in mathematics: Improving outcomes, building identification models, and understanding disability. Journal of Learning Disorders 38(4), 350-352.

Fuson, K. C. (1990). Issues in place-value and multidigit addition and subtraction learning and teaching. Journal for Research in Mathematics Education, 21(4), 273-280.

Gadanidis, G. (2004). The pleasure of attention and insight. Mathematics Teaching, 186, March, 10-13.

Geary, D. C. (2010). Mathematical disabilities: Reflections on cognitive, neuropsychological, and genetic components. Learning and Individual Differences, 20 (2010), 130-133.

Gersten, R. (1999). Number sense: Rethinking arithmetic instruction for students with mathematical disabilities. Journal of Special Education, $44,18-28$.

Gersten, R., \& Newman-Gonchar, R. (2011). Understanding RTI in mathematics: Proven methods and applications. Reston, VA: National Council of Teachers of Mathematics.

Ke, F., \& Grabowski, B. (2007). Gameplaying for maths learning: Cooperative or not? British Journal of Educational Technology, 38(2), 249-259.

Ma, L. (1999). Knowing and teaching elementary mathematics: Teachers' understanding of fundamental mathematics in China and the United States. Mahwah, NJ: Erlbaum.

Markovits, Z., \& Sowder, J. (1994). Developing number sense: An intervention study in grade 7. Journal for Research in Mathematics Education, 5(1), 4-29.

Nardi, E., \& Steward, S. (2002). I would be the best mathematician in the world . . . if I actually enjoyed it. Mathematics Teaching, 179, 41-44.

National Research Council, Mathematics Learning Study Committee, Center for Education, Division of Behavioral and Social Sciences and Education. (2001). The strands of mathematical proficiency. In J. Kilpatrick, J. Swafford, \& B. Findell (Eds.), Adding it up: Helping children learn mathematics (pp. 115-155). Washington, DC: National Academy Press.

Patton, M. Q. (1990). Qualitative evaluation and research methods (2nd ed.). Newbury Park, CA: Sage.

Shumway, J. F. (2011). Number sense routines: Building numerical literacy every day in grades $K-3$. Portland, ME: Stenhouse Publishers.
Strauss, A. L., \& Corbin, J. M. (1990). Basics of qualitative research: Grounded theory procedures and techniques. Thousand Oaks, CA: Sage.

Threlfall, J. (2002). Flexible mental calculation. Educational Studies in Mathematics, 50(1), 29-47.

Van De Walle, J. A. (2004). Elementary and middle school mathematics: Teaching developmentally. Boston, MA: Pearson Education.

Varelas, M., \& Becker, J. (1997). Children's developing understanding of place value: Semiotic aspects. Cognition and Instruction, 15(2), 265-286.

Varol, F., \& Farran, D. (2007). Elementary school students' mental computation proficiencies. Early Childhood Education Journal, 35(1), 89-94.

Vaughn S. (2011). Foreword. In R. Gersten \& R. Newman-Gonchar (Eds.), Understanding RTI in mathematics: Proven methods and application (pp. $\mathrm{xv}-\mathrm{xvi}$ ). Reston, VA: National Council of Teachers of Mathematics.

Vosniadou, S., \& Brewer, W. F. (1987). Theories of knowledge restructuring in development. Review of Educational Research, 57(1), 51-67.

Vygotsky, L. S. (1978). Mind in society: The development of higher psychological processes. Cambridge, MA: Harvard University Press.

Webb, D. C., Boswinkel, N., \& Dekker, T. (2008). Beneath the tip of the iceberg: Using representations to support student understanding. Mathematics Teaching in the Middle School, 14 (2), 110-113.

Westenskow, A. (2012). Equivalent fraction learning trajectories for students with mathematical learning difficulties when using manipulatives (Doctoral Dissertation, Utah State University, Logan, Utah).

Westenskow, A., Boyer-Thurgood, J., \& Moyer-Packenham, P. S. (2015). A window into mathematical support: How parents' perceptions change following observations of mathematics tutoring. Journal of Research in Childhood Education, 29(4), 458-475.

Westenskow, A., \& Moyer-Packenham, P. (2016). Using an iceberg intervention model to understand equivalent fraction learning when students with mathematical learning difficulties use different manipulatives. The International Journal for Technology in Mathematics Education, 23(2), 45-63.

Westenskow, A., Moyer-Packenham, P. S., \& Child, B. (2014, January). Developing number sense flexibility: Effectiveness of a Tier II summer intervention program. Proceedings of the 12th Annual Hawaii International Conference on Education (pp. 1193-1201), Honolulu, Hawaii.

Yang, D. C. (2003). Teaching and learning number sense-an intervention study of fifth grade students in Taiwan. International Journal of Science and Mathematics Education, 1(1), 115-134.

Young-Loveridge, J. M. (2004). Effects on early numeracy of a program using number books and games. Early Childhood Research Quarterly, 19(1), 82-98.

Arla Westenskow is the director of the TIME (Tutoring Interventions and Mathematics Enrichment) clinic in the Department of Mathematics Education and Leadership at Utah State University. Dr. Westenskow can be reached at arlawestenskow@gmail.com.

Patricia Moyer-Packenham is Director and Professor of Mathematics Education and Leadership in the School of Teacher Education and Leadership at Utah State University. Dr. Moyer-Packenham can be reached at patricia.moyer-packenham@usu.edu.

Barbara Child is the mathematics specialist at Logan City School District. Ms. Child can be reached at mathwoman28@gmail.com. 